\title{
Rosetta Mission: Electron Scattering Cross Sections-Data Needs and Coverage in BEAMDB Database
}

\author{
Bratislav P. Marinković $^{1, *}$, Jan Hendrik Bredehöft ${ }^{2}$ (D) , Veljko Vujčić $^{3}$, Darko Jevremović ${ }^{3}$ and \\ Nigel J. Mason ${ }^{4}$ \\ 1 Institute of Physics Belgrade, University of Belgrade, Pregrevica 118, Belgrade 11080, Serbia \\ 2 Institute for Applied and Physical Chemistry, Fachbereich 2 (Biologie/Chemie), Universität Bremen, \\ Leobener Straße 5, Bremen 28359, Germany; jhbredehoeft@uni-bremen.de \\ 3 Astronomical Observatory Belgrade, Volgina 7, Belgrade 11000, Serbia; veljko@aob.rs (V.V.); \\ darko@aob.rs (D.J.) \\ 4 Department of Physical Sciences, The Open University, Milton Keynes MK7 6AA, UK; \\ N.J.Mason@open.ac.uk \\ * Correspondence: braislav.marinkovic@ipb.ac.rs; Tel.: +381-11-316-0882
}

Received: 21 September 2017; Accepted: 14 November 2017; Published: 17 November 2017

\begin{abstract}
The emission of [O I] lines in the coma of Comet 67P/Churyumov-Gerasimenko during the Rosetta mission have been explained by electron impact dissociation of water rather than the process of photodissociation. This is the direct evidence for the role of electron induced processing has been seen on such a body. Analysis of other emission features is handicapped by a lack of detailed knowledge of electron impact cross sections which highlights the need for a broad range of electron scattering data from the molecular systems detected on the comet. In this paper, we present an overview of the needs for electron scattering data relevant for the understanding of observations in coma, the tenuous atmosphere and on the surface of 67P/Churyumov-Gerasimenko during the Rosetta mission. The relevant observations for elucidating the role of electrons come from optical spectra, particle analysis using the ion and electron sensors and mass spectrometry measurements. To model these processes electron impact data should be collated and reviewed in an electron scattering database and an example is given in the BEAMD, which is a part of a larger consortium of Virtual Atomic and Molecular Data Centre-VAMDC.
\end{abstract}

Keywords: electron scattering; cross sections; Rosetta mission; atomic and molecular databases

\section{Introduction}

The Rosetta spacecraft was launched in 2004 as a part of the European Space Agency (ESA) space program, with the mission to rendez-vous with, orbit and place a lander upon periodic comet 67P/Churyumov-Gerasimenko. Rosetta was in orbit with the cometary nucleus from 2014 to September 2016 during which time it was able to closely examine how the coma of the comet and the frozen comet's surface changed relative to distance from the Sun. On November 2014 Rosetta dispatched a lander, Philae, which touched down on the comet's surface and recorded, for the first time, in situ data from the surface. This pioneering mission has provided us with new and unexpected data that are changing our understanding of the structure and chemistry of cometary systems and their role in the evolution of our solar system and possible origins of life on Earth. For example, the D to H ratio in cometary water ice is very different from that on Earth and, among the other similar findings, challenges the hypothesis that water on Earth was brought by cometary impact [1].

In this paper, we will review another intriguing and unexpected result from the Rosetta mission namely the role of electron induced dissociation in the comet's coma. The data needed to model electron 
processes in cometary coma and its possible relevance to the formation but also the dissociation and fragmentation of molecules observed by Rosetta instruments, will be discussed together with the current data available and the databases in which such data may be found.

\section{Rosetta Instruments and Their Observation of Electron Scattering Processes in the Cometary Coma}

Rosetta orbiter carried eleven different complex scientific instruments, while the Philae lander had ten instruments. Only those that are immediately relevant for the case study of the role of electrons in comas and the detection of more complex species that may be formed by electron induced chemistry will be reviewed here.

\subsection{FUV Emissions Measured by the ALICE Instrument}

ALICE was a far-ultraviolet (FUV) imaging spectrograph that could specially resolve spectra in the range from 70 to $205 \mathrm{~nm}$. Coma emission and the reflected solar spectrum from the nucleus were recorded using ALICE throughout the Rosetta encounter. The coma was identified by a spectrum that contains several features that are weak in the solar spectrum and do not appear in the reflected light from the nucleus [2]. Besides strong hydrogen Lyman lines, lines from oxygen multiplets at 98.9, 115.2, 130.4 and $135.6 \mathrm{~nm}$ were observed, as were weak multiplets from carbon C I lines at 156.1 and $165.7 \mathrm{~nm}$ and emission bands coming from CO. The surprise was the O I line at $135.6 \mathrm{~nm}$, originated from the forbidden transition ${ }^{5} \mathrm{~S}^{\mathrm{o}}{ }^{3} \mathrm{P}$ since this is usually not seen in comas. The presence of this line and the intensity ratio of $\mathrm{H} \mathrm{I}$ and $\mathrm{O}$ I multiplets is characteristic of the process of electron dissociative excitation of water molecules [3] and led Feldman et al. [2] to establish that electron collisions with $\mathrm{H}_{2} \mathrm{O}$ is the dominant source of these emissions. Similarly, they attributed C I emissions to electron dissociative excitation of $\mathrm{CO}_{2}$. The relative contribution of the UV and electron impact to the dissociation processes are dependent on the location with respect to the nucleus and the heliocentric distance as discussed in $[4,5]$.

\subsection{Observations from the OSIRIS Instrument}

OSIRIS (Optical, Spectroscopic and Infrared Remote Imaging System) was one of Rosetta's major imaging systems equipped with a wide-angle camera (WAC) and a series of narrow band filters covering range from 245 to $640 \mathrm{~nm}$ and two broad band filters, green and red, covering the spectra up to $720 \mathrm{~nm}$. This instrument recorded coma emission lines and specifically targeted to the transitions of $\mathrm{O}, \mathrm{OH}, \mathrm{CN}, \mathrm{CS}, \mathrm{NH}$ and $\mathrm{NH}_{2}$. The mapping of water distribution was possible indirectly through observations of $\mathrm{O} \mathrm{I}$ and $\mathrm{OH}$ bandpass filters. The $\mathrm{O}$ I filter covers the forbidden transitions from the $\mathrm{O} \mathrm{I}\left(2 \mathrm{p}^{4}\right){ }^{1} \mathrm{D}$ state which is populated directly by photodissociation of $\mathrm{H}_{2} \mathrm{O}$ molecules, while the $\mathrm{OH}$ filter covers the (0-0) band of the $\mathrm{A}^{2} \Sigma^{+}-\mathrm{X}^{2} \Pi$ transition of $\mathrm{OH}$, centred at about $308.5 \mathrm{~nm}$, which is excited almost entirely by fluorescence of sunlight as pointed out in [6]. The O I ${ }^{1} \mathrm{D}$ state can be also populated from the transition from the O I $\left(2 \mathrm{p}^{4}\right)^{1} \mathrm{~S}$ state. Within the $\mathrm{CN}$ filter lies an emission line $\mathrm{B}^{2} \Sigma^{+}-X^{2} \mathrm{~S}^{+}(0,0)$ at $388 \mathrm{~nm}$, within the $\mathrm{NH}_{2}$ filter there is a wide emission band $\tilde{\mathrm{A}}^{2} \mathrm{~A}_{1}-\mathrm{X}^{2} \mathrm{~B}_{1}(0,10,0)$ and the NH filter covers the NH $\mathrm{A}^{3} \Pi_{1}-X^{3} \Sigma^{-}(0-0)$ transition [6].

From this data Bodewits et al. [6] derived column densities and calculated global production rates using the standard Haser model. They found that the water production rates derived from $\mathrm{OH}$ are larger than those derived from [O I], OH and [O I] photolysis. Indeed, they analysed all production rates and found a much larger drop in water production rates than diurnal variation can explain. Therefore, they concluded that the photo-dissociation and fluorescence could solely explain the processes resulting in the $\mathrm{OH},[\mathrm{O}$ I], $\mathrm{CN}$ and $\mathrm{NH}$ emission observed in the inner coma and that the fragments might emanate from different parent species and/or be formed by other processes [6]. One additional process is electron induced dissociation of water, when including this in their model a much better fit was obtained, indeed electron driven dissociation of water was found to be dominant in agreement with Feldman et al. [2]. 


\subsection{Detection of Organic Molecules on the Comet Surface-COSAC Mass Spectrometry}

The COSAC (COmetary SAmpling and Composition) experiment and Ptolemy were two gas analysers on the Philae lander built to monitor the chemical composition of the surface of comet 67P. Due to difficulties in landing Philae was not able to deploy all of its instruments as planned and the drill could not be deployed to collect samples for in-situ analysis. However, seven measurements were made by both COSAC and Ptolemy during Philae's hopping and at its final landing site in a so-called 'sniff mode' that had no active sampling but rather just ionized whatever molecules were present in the ionization chamber of the mass spectrometer. The sample with the richest data was acquired a few minutes after the first touchdown with subsequent decay of signal strength in the other six measurements. Both instruments measured a nearly identical decay of both the water $(m / z 18)$ and $\mathrm{CO}(\mathrm{m} / \mathrm{z} 28)$ peaks. However, in the COSAC measurements the peak at $\mathrm{m} / \mathrm{z} 44$ decays much slower than all the other ion species, including the water peak and, the $m / z 44$ peak also decays much slower in the COSAC measurements than in the Ptolemy data. From these results, it has been concluded that COSAC analysed a regolith sample from the cometary nucleus in situ while Ptolemy measured cometary gas from the ambient coma [7].

The compounds detected by COSAC are listed in Table 1. All of the larger molecules can be formed from the smaller compounds carbon monoxide $(\mathrm{CO})$, methane $\left(\mathrm{CH}_{4}\right)$, water $\left(\mathrm{H}_{2} \mathrm{O}\right)$ and ammonia $\left(\mathrm{NH}_{3}\right)$ by simple addition reactions [8]. The $m / z 44$ peak measured by COSAC was likely dominated by organic species, e.g., from acetaldehyde $\left(\mathrm{C}_{2} \mathrm{H}_{4} \mathrm{O}\right)$, formamide $\left(\mathrm{HCONH}_{2}\right)$ and acetamide $\left(\mathrm{CH}_{3} \mathrm{CONH}_{2}\right)$, whereas the peak measured by Ptolemy was interpreted to be mostly due to $\mathrm{CO}_{2}$. Recently, a comparison and comparative analysis of the Rosetta mass spectrometers (COSAC/Ptolemy/ROSINA) that puts some question mark on the presence of some of the nitrogen-bearing species was presented [9]. Ptolemy measurements confirmed many of the species observed by COSAC and through observation of regular peaks in the observed mass distributions indicated the presence of a sequence of compounds with additional - $\mathrm{CH}_{2}$ - and -O- groups (mass/charge ratios 14 and 16, respectively) which confirms COSAC's observations of acetaldehyde and may be explained by the presence of a radiation-induced polymer at the surface. Ptolemy measurements also indicated an apparent absence of aromatic compounds such as benzene and neither $\mathrm{H}_{2} \mathrm{~S}$ nor $\mathrm{SO}_{2}$ were observed [10]. Ammonia believed to be the precursor of $\mathrm{N}$ containing compounds was not unambiguously detected by either Ptolemy or COSAC, probably due to its tendency to adsorb on stainless steel surface.

Table 1. List of molecules identified on the comet nucleus of comet $67 \mathrm{P}$ by the COSAC instrument [8]. Abundances are given normalized to water, which is the most abundant compound.

\begin{tabular}{ccc}
\hline Name of Compound & Sum Formula & Abundance wrt Water \\
\hline Methane & $\mathrm{CH}_{4}$ & $0.5 \%$ \\
Water & $\mathrm{H}_{2} \mathrm{O}$ & $100 \%$ \\
Hydrogen cyanide & $\mathrm{HCN}$ & $0.9 \%$ \\
Carbon monoxide & $\mathrm{CO}$ & $1.2 \%$ \\
Methylamine & $\mathrm{CH}_{3} \mathrm{NH}_{2}$ & $0.6 \%$ \\
Acetonitrile & $\mathrm{CH}_{3} \mathrm{CN}$ & $0.3 \%$ \\
Isocyanic acid & $\mathrm{HNCO}^{2}$ & $0.3 \%$ \\
Acetaldehyde & $\mathrm{CH}_{3} \mathrm{CHO}$ & $0.5 \%$ \\
Formamide & $\mathrm{HCONH}_{2}$ & $1.8 \%$ \\
Ethylamine & $\mathrm{C}_{2} \mathrm{H}_{5} \mathrm{NH}_{2}$ & $0.3 \%$ \\
Methyl isocyanate & $\mathrm{CH}_{3} \mathrm{NCO}_{2}$ & $1.3 \%$ \\
Acetone & $\mathrm{CH}_{3} \mathrm{COCH}$ & $0.3 \%$ \\
Propionaldehyde & $\mathrm{C}_{2} \mathrm{H}_{5} \mathrm{CHO}$ & $0.1 \%$ \\
Acetamide & $\mathrm{CH}_{3} \mathrm{CONH} \mathrm{HN}_{2}$ & $0.7 \%$ \\
Glycolaldehyde & $\mathrm{CH}_{2} \mathrm{OHCHO}$ & $0.4 \%$ \\
Ethylene glycol & $\mathrm{HOC}_{2} \mathrm{H}_{4} \mathrm{OH}$ & $0.2 \%$ \\
\hline
\end{tabular}


Recent experiments on the irradiation of ice mixtures reveal that many of the larger molecules can be formed by electron bombardment, often at low energies and this will be discussed further in Section 5. Indeed, the bombardment and dissociation of ice species has been proposed as a route by which molecular oxygen can form. One of the most unexpected observations of Rosetta through the Rosina instrument was the detection of molecular oxygen as the fourth most abundant gas in the atmosphere of comet 67P. Oxygen is reactive so it was felt that it is unlikely to survive long periods in space. The amount of molecular oxygen detected showed a strong relationship to the amount of water measured at any given time, suggesting that their origin on the nucleus and release mechanism are linked and that irradiation of water ice leading to oxygen production and storage in the ice is a plausible mechanism for oxygen formation on a comet [11].

\subsection{Electrons in the Cometary Coma}

That there are copious amounts of electrons to induce such dissociative excitation was confirmed by ion and electron sensors (RPC-IES) on the Rosetta craft. Concentrations of particles and their time evolution in inner coma plasma was measured by Rosetta Plasma Consortium (RPC) [12] using a set of sensors developed for this purpose. The Ion and Electron Sensor (IES) was an electrostatic plasma analyser that covered an energy/charge range from $1 \mathrm{eV} / \mathrm{e}$ to $22 \mathrm{keV} / \mathrm{e}$ with a resolution of 4\% [13]. The sensor provided 3D ion and electron distributions over the whole measured energy range. It was capable of simultaneously measuring electrons and positive ions with the single entrance aperture owing to two back-to-back top-hat geometry analysers. The LAP instrument (Langmuir probes) measured the plasma density in the range of $\left(10^{0}-10^{6} \mathrm{~cm}^{-3}\right)$, electron temperature $\left(10^{2}-10^{5} \mathrm{~K}\right)$ and plasma flow velocity (up to $10^{4} \mathrm{~ms}^{-1}$ ). The LAP also measured the AC electric field up to $8 \mathrm{kHz}$ [14]. The LAP was complemented by the Mutual Impedance Probe, MIP which probes the plasma and measured the natural plasma frequency which yields the electron density in the range from $2 \mathrm{~cm}^{-3}$ to $1.5 \times 10^{5} \mathrm{~cm}^{-3}$ and temperature from $30 \mathrm{~K}$ to $10^{6} \mathrm{~K}[15]$.

Depending on the comet distance from the Sun, both the solar wind and solar radiation interact with its nucleus and inner coma shielded by comet's own atmosphere and ionosphere. Cometary ions are created by photoionization of neutral species, mainly like $\mathrm{H}_{2} \mathrm{O}$ and $\mathrm{CO}_{2}$ and their products from photodissociation, and by charge transfer with solar wind protons [16]. Solar wind electrons in interplanetary space typically have Maxwellian distribution functions with thermal energies of several $\mathrm{eV}$ to tens of $\mathrm{eV}$ [13]. This energy distribution of electrons differs from one created by photoionization of cometary neutrals by solar radiation in the cometary comas at certain distances from the Sun. Electrons of cometary origin are mainly the product of photochemistry, originating from direct photoionization and from Auger processes. They are thermalized by collisions, elastic and inelastic.

The electron density in the coma was measured complementary by the RPC Langmuir Probe (LAP) and Mutual Impedance Probe (MIP). The first findings of the spatial distribution of the plasma near comet $67 \mathrm{P} / \mathrm{CG}$ showed a highly structured pattern that indicated an origin from local ionization of neutral gas. The electron density fell off with distance as $1 / \mathrm{r}$ in the range from $8 \mathrm{~km}$ from the nucleus up to $260 \mathrm{~km}$ [17]. Edberg et al. [17] concluded that this is in accord with a model in which the ionization of a neutral gas is expanding radially from the comet nucleus and when there is no significant recombination or other loss source for the plasma. However, they warned that the observed data have a large scatter around fitted $1 / \mathrm{r}$ curve and that results could be an average effect of combination of transport electric fields and solar wind.

From such data, the suprathermal energy distribution of electrons could be derived. The electron energy distribution near the comet depends on the comet distance from perihelion and mass loading process when the atoms and molecules in the cometary coma are photoionized and then interact with the solar wind flow. It spans from the energy distribution of the solar wind itself to the modified distribution where electrons are significantly decelerated as a consequence of magnetic field causing regions to pile-up. The mass loading process is connected to the outgassing rate of the comet. The formation of suprathermal electrons which are accelerated from a few eV upward 
to hundreds of $\mathrm{eV}$, thus can play an important role in the electron driven chemistry of the comet. The Rosetta IES sensor recorded the presence of suprathermal electrons at larger distances than expected from the previous models of such weakly outgassing comets [18]. The observed electron energy distributions change by reducing a heliocentric distance from pure solar wind distribution to non-Maxwellian one that include suprathermal electrons showing maxima at energies from $10 \mathrm{eV}$ to $300 \mathrm{eV}$ [18]. Clark et al. [18] hypothesize that the most likely mechanisms of creating accelerated electron distributions are heating by waves generated by the pick-up ion instability and by the mixing of cometary photoelectrons, secondaries and solar wind electrons.

Further statistical analysis of Rosetta IES sensor recordings by performing fitting procedures that involve two separate sub-populations of electrons below and above $8.6 \mathrm{eV}$ mean energy [19] revealed different relationships between their density and temperature and possible mechanisms of creating suprathermal electrons. Broiles et al. [19] suggested that electrons above $8.6 \mathrm{eV}$ are being heated by waves driven by counter streaming solar wind protons. This conclusion arises from the observations that the population of electrons above $8.6 \mathrm{eV}$ correlates well with the density of local neutrals, while the sub-population below $8.6 \mathrm{eV}$ is dominated by the local magnetic field strength. Recently, Deca et al. [20] have used a fully 3D kinetic model to simulate the ion and electron dynamics of the solar wind interaction with a weakly outgassing comet 67P. They used a detailed kinetic treatment of the electron dynamics in order to cover energy distribution of electrons and to identify the origin of the warm and suprathermal electrons.

Electron energy ranges that correspond to the relevant processes in electron collisions with atoms and molecules are shown in Figure 1. The elastic cross section is dominating over low electron energies and usually is prominent even at higher energies where the ionization cross section becomes comparable in magnitude. Vibrational excitations are important at low energies but they also extend to higher energies due to resonance decay. Attachment and dissociation processes are relevant in certain domains, in water between 6 to $9 \mathrm{eV}$ and 20 to $200 \mathrm{eV}$, respectively (see the summery figure of cross sections in [3]), but due to dissociative electron attachment (DEA) these processes may extend to very low energies. The production of radiation due to de-excitation depends on excitation energy levels. For water molecule production of Lyman alpha radiation has a high cross section in the electron energy range from 50 to $200 \mathrm{eV}$.

\section{Electron driven processes}

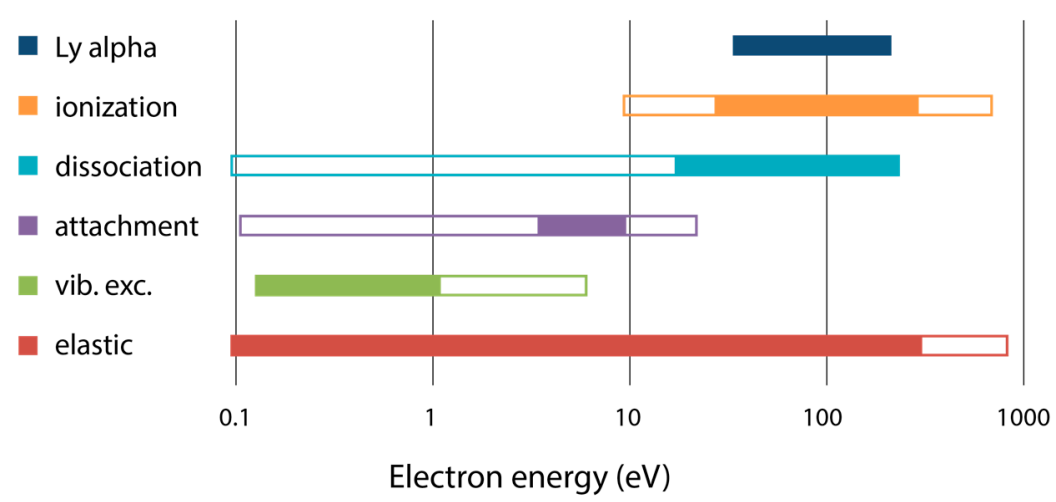

Figure 1. Electron energy ranges that correspond to the relevant processes in collisions with atoms and molecules. Full colour corresponds to the specific case of water (data taken from Itikawa and Mason [3]) while the open bars are extended ranges that correspond to the majority of atomic species: red, elastic scattering; green, vibrational excitations; violet, attachment; blue, dissociation; orange, ionization; darkblue, Lyman alpha. 


\section{Atomic and Molecular Data Needed for Analysing Electron Scattering Processes Relevant to Comet 67P}

Despite the evidence for electron induced processes in comets many of the discrete collision processes necessary to quantify such electron driven chemistry remain uncertain. In order to develop a predictive model of cometary coma and the comet's 'atmosphere' it is necessary to assemble a 'database' of relevant electron collision processes with the different atomic and molecular species observed (or indeed inferred) from Rosetta. As discussed above Rosetta's ROSINA, as well as Ptolemy and COSAC on the Philae lander, have revealed a rich chemical inventory that would require a large atomic and molecular physics database to model all possible processes. However, if a sensitivity analysis is performed the number of important species contributing to the model may be reduced to a minimum (more manageable) number of reactions. The dominant molecules are water, $\mathrm{CO}$ and $\mathrm{CO}_{2}$. The presence of $\mathrm{HCN}$ as the source of $\mathrm{CN}$ radicals and ammonia as source of $\mathrm{NH}$ and $\mathrm{NH}_{2}$ is widely accepted while the simple hydrocarbons $\mathrm{C}_{2} \mathrm{H}_{2}$ and $\mathrm{C}_{2} \mathrm{H}_{6}$ are assumed to be the source of $\mathrm{C}_{2}$, indeed $\mathrm{C}_{2} \mathrm{H}_{6}$ concentrations were unusually high in comet $67 \mathrm{P}$ [21]. Methane has been identified in many comets and is found in comet 67P. As discussed above several oxygen containing species were detected and apart from the ubiquitous water methanol $\mathrm{CH}_{3} \mathrm{OH}$ may be an important primary compound. The primary source of sulphur compounds may be $\mathrm{H}_{2} \mathrm{~S}$ but $67 \mathrm{P}$ is depleted in all other sulphur bearing species $\left(\mathrm{CS}_{2}, \mathrm{OCS}\right.$ and $\left.\mathrm{SO}_{2}\right)$ compared to other comets [22]. Thus, in developing an electron chemistry model of comet $67 \mathrm{P}$ it is necessary to have a good data base for electron interactions with $\mathrm{H}_{2} \mathrm{O}, \mathrm{CO}$, $\mathrm{CO}_{2}, \mathrm{CH}_{4}, \mathrm{C}_{2} \mathrm{H}_{6}, \mathrm{CH}_{3} \mathrm{OH}, \mathrm{NH}_{3}, \mathrm{HCN}$ and $\mathrm{H}_{2} \mathrm{~S}$. The status of such a database will be discussed below but first it is necessary to understand the corollary for a 'good' database.

\subsection{Databases}

Many databases exist in order to assemble datasets and communicate them to different audiences. The NIST database collection (https: / srdata.nist.gov/gateway / gateway?dblist=0) is one of the best known providing details of the structure, spectroscopy and fundamental parameters (ionization and dissociation energies) of many atoms and molecules. The need for large datasets has led to several communities investing in establishing data centres which assemble and maintain databases. For example, the fusion community has, for several decades, compiled databases in order to model plasmas in tokamak reactors and to provide data for diagnostic tools used in such plasmas. Another example of large collection of collisional data is the LXCaT database [23], which provides electron and ion scattering cross sections, swarm parameters (mobility, diffusion coefficient, etc.), reaction rates, energy distribution functions, etc. and other data required for modelling low temperature plasmas. Similarly, the astronomical community has needed large databases to interpret its observations, these include not only spectroscopic databases but also databases of chemical reaction rates (e.g., KIDA [24]) are necessary to understand the rich inventory of molecules that have been observed in the interstellar medium.

Many databases are simple collections of data but more recently the design and operation of databases has been refined. The development of IT tools has allowed data to be provided on-line, downloadable in a range of formats and allows new data to be added quickly, ensuring that the data is up to date. Previously data was reviewed and published in journal reviews which once published became gradually out of date until the next review, often a decade later (e.g., [25]). The opportunity to add new data quickly not only ensures that the latest data is adopted by the community but also reduces the likelihood of fragmentation amongst the community with different groups using different data sets in accord with their knowledge (or more commonly lack of knowledge) of the data available.

Simple assembly of data alone is not, however, the most effective form of databases. The 'user' community requires guidance as to what data to adopt. Users rarely have the necessary experience to select one dataset over another and therefore each may choose different sets, leading to systematic problems. For example, if different datasets are used in different models, cross comparison of such models is difficult and it may be hard to distinguish between the different physical and chemical 
hypotheses in different models from the data used in the model to explore such effects. Therefore, databases should provide 'recommended data' which is the data that the expert community providing such data believes is the optimal data reflecting state of the art measurements or calculations. These values can be updated as new data becomes available. However, when changing recommended data, it is essential to ensure that it is still 'consistent' For example in presenting a comprehensive set of electron impact cross sections the individual cross sections (elastic and inelastic (including ionization excitation etc.) should, when summed, be consistent with the recommended data for total cross sections. Databases should also present data with stated estimates of uncertainties, particularly when presenting its own composite data from several different datasets.

\subsection{VAMDC and BEAMDB Databases}

The Virtual Atomic and Molecular Data Centre-(VAMDC) and Belgrade Electron Atom and Molecule Database-(BEAMDB) are two examples of new generation of databases. The VAMDC Consortium is a worldwide consortium which federates atomic and molecular databases through an e-science infrastructure to provide easy access to data from different databases via a single portal http:/ / portal.vamdc.eu. About $90 \%$ of the inter-connected databases are focused on data that are used for the interpretation of astronomical spectra and for modelling in many fields of astrophysics and astrochemistry, although recently the VAMDC Consortium has connected databases from the radiation damage and the plasma communities which makes it suitable for medical and industrial applications [26]. While VAMDC does not itself select and analyse data it ensures data from its component databases are accessible in a single format and ascribe to general good practices as discussed above. The VAMDC Consortium includes new databases and services on a case by case basis during annual general scientific and technical meetings.

VAMDC provides its data in a XSAMS output. XSAMS is an XML representation of an atomic and molecular data model. The system allows for distributed querying of data via the VAMDC-TAP protocol, an implementation-agnostic standard, where data providers can build their models in their own fashion and map them to the VAMDC model via a dedicated dictionary [27].

The Belgrade Electron Atom and Molecule Database-(BEAMDB) [28] is an application, database and a VAMDC node which contains data for elementary processes of electron scattering by atoms and molecules. The database covers collisional data of electron interactions with atoms and molecules in the form of differential and integrated cross sections as well as energy loss spectra. The data is stored in a relational (MySQL) database, upon a static model specifically suited to this dataset but easily extendable. There have already been several migrations of the model, the latest of which is an extension to enable storing non-neutral molecules. Currently, there are 22 species stored in the database ( 11 atoms and 11 molecules), presented in 71 states, involved in 59 collision processes. The web interface (http:/ / servo.aob.rs/emol) enables on-site querying of data via an AJAX-enabled web form. The application is implemented in Django, a Python web framework and hosted on an Apache web server at the Astronomical Observatory in Belgrade.

The BEAMDB is a collisional database where several types of collisions are included: Elastic, Electronic Excitation, (Total) Inelastic, Ionization, and Total Scattering as well as electron spectroscopic data such as Energy-loss Spectra and Threshold Photoelectron Spectra. Cross sections are of several different kinds: Differential, Integral, Total, Momentum Transfer, Viscosity. Specific data that are maintained in the BEAMDB are differential cross sections (DCS) for elastic scattering and excitation of atoms and molecules. These are 3D entries since DCS depend on both electron impact energy and scattering angle. This requires two $X$ columns while the $Y$ column is also associated with the column representing uncertainty of data points. An example of the XSAMS output of such kind of data for He excitation is shown in Figure 2.

Producing a plot of DCS data is not available at the current stage of database development, but such data can be visualized by using either VAMDC portal or alternatively the RADAM (RADiation DAMage) database portal (http:/ / radamdb.mbnresearch.com/). The general structure of RADAM 
databases covers electron/positron interactions, ionic and photonic interactions, multiscale radiation damage phenomena and radiobiological phenomena occurring at different time, spatial and energy scales in irradiated targets [29]. Examples of DCS surfaces for elastic electron scattering by helium atom and formamide $\left(\mathrm{CH}_{3} \mathrm{NO}\right)$ molecule are shown in Figure $3 \mathrm{a}, \mathrm{b}$, respectively.

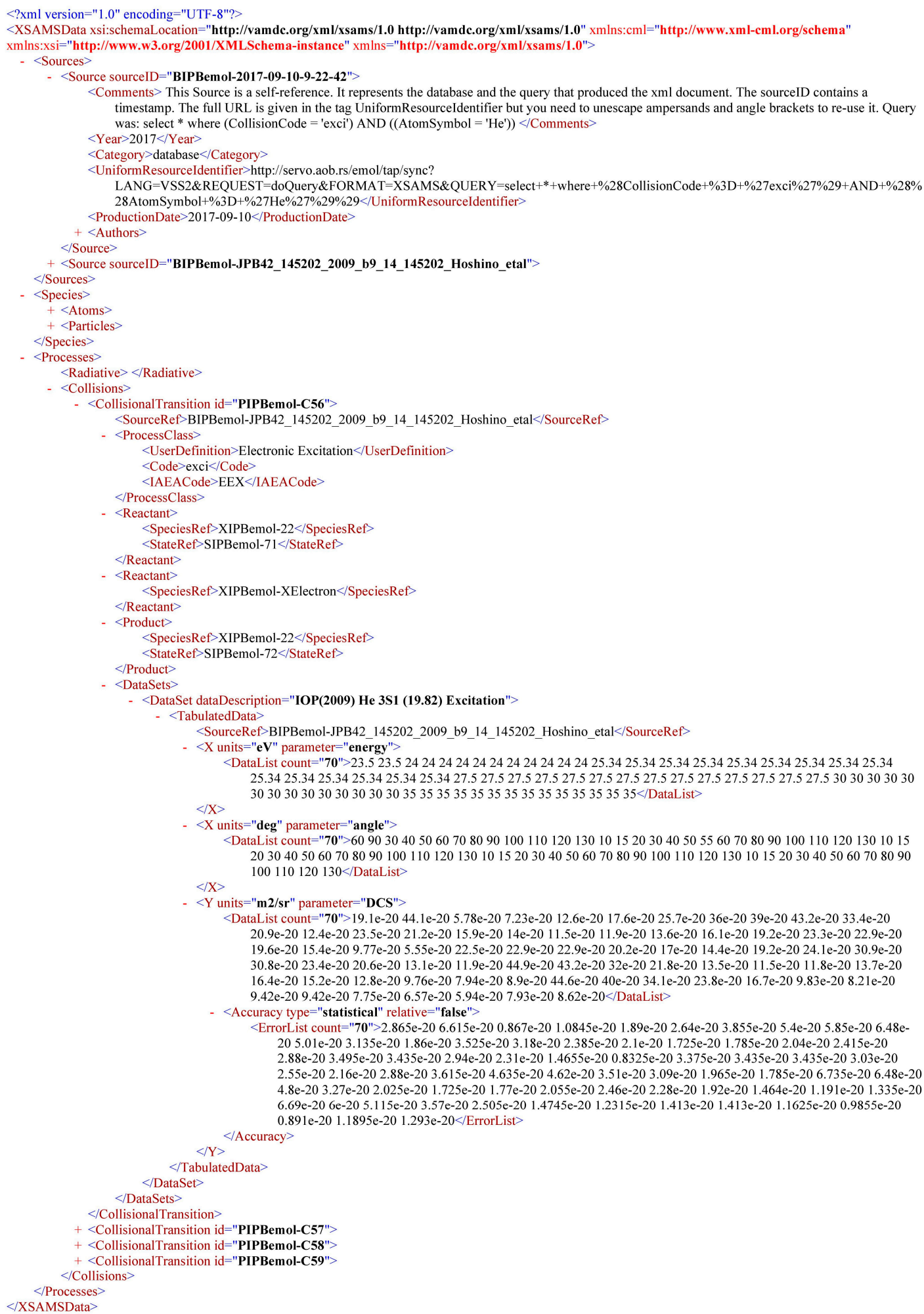

Figure 2. XSAMS output table for differential cross section data for He electron excitation. 


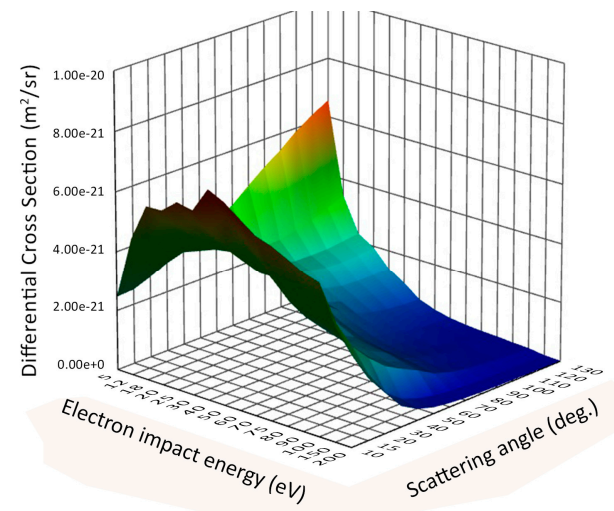

(a)

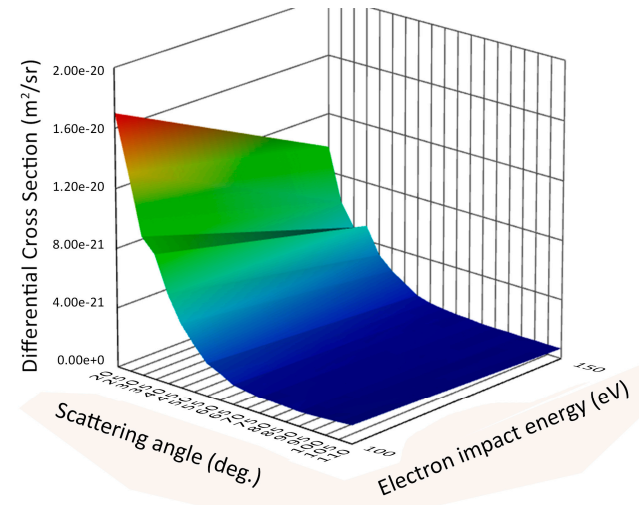

(b)

Figure 3. DCS surfaces as retrieved from RADAM database [29] for elastic electron scattering by: (a) He atom—data points are taken from ref. [30]; (b) Formamide molecule—data points are taken from ref. [31].

Initially BEAMDB was designed to maintain data of electron collisions with neutral species, atoms and molecules mainly in their ground state and exceptionally in excited state. However, by broadening the scope toward astrophysical applications, more specifically to the processes of comas that involve electrons, the database has been upgraded to include electron collisions with ions. The most recent data set included in BEAMDB is the one of electron ionisation cross sections of $\mathrm{CN}^{+}$cations [32]. In the next few months BEAMDB will expand to include many more molecular systems including those needed to study the electron chemistry of comet $67 \mathrm{P}$.

\section{Electron Scattering Processes and Cross Sections-Data Needs}

To understand and treat by models, processes in cometary plasmas is a very challenging task since many parameters need to be taken into account in order to cover the variety of comet types and their heterogeneity. One has to consider the changing of comet distances from the Sun and hence the level of irradiation and solar wind interactions both with the comet surface and cometary plasma environment. Nevertheless, models have been developed and set of processes reviewed, including data analysis used in such models. Particles from the solar wind, secondary electrons created in plasmas and photoelectrons, produce further events of excitation, ionization and dissociation with the consequence of enhanced chemical reactions and light emission. However, comets are composed of water, silicates and carbonaceous molecules ( $\mathrm{CO}, \mathrm{CO}_{2}$ and hydrocarbons) [33]. Recently, modelling of plasma processes in cometary and planetary atmospheres has been performed by Campbell and Brunger [34] with an emphasis on the role of electron-impact excitation processes. They concluded in the case of comet Hale-Bopp that electron-impact could account for $40 \%$ of the fluorescence emissions of the fourth positive bands $\left(\mathrm{A}^{1} \Pi-\mathrm{X}^{1} \Sigma^{+}\right)$of $\mathrm{CO}[35]$ and thus reducing calculated outgassing rates. Even more, their later paper [36] was focussed on electron initiated chemistry in atmospheres.

Reviews of cross section data and processes that cover electron scattering and excitations are numerous and they cover interactions with atoms [37,38], diatomic molecules [37,39], species in interstellar clouds [40] or concentrate on specific targets of triatomic molecules like water [3] or $\mathrm{CO}_{2}$ and $\mathrm{N}_{2} \mathrm{O}$ [40]. Anzai et al. [41] stressed that any recommended values of cross section data currently maintained in different databases might need to be updated due to the development of new experimental techniques and theoretical methods. The number of established benchmark cross sections is rather small.

The energy of the electrons available for electron interactions with atoms and molecules in the cometary coma 'atmosphere' is such that all electron scattering processes are relevant, thus a large amount of data is required if a model of electron induced processing is to be included in a simulation 
model of comet 67P. In this section, the status of our knowledge of such relevant cross sections will be reviewed for the primary molecules defined in Section 3.

\subsection{Elastic Electron Scattering and Cross Sections}

Elastic scattering conserves the kinetic energy of the colliding particles. This means that quantum numbers that determine the energy are unchanged but other quantum numbers corresponding to degenerate states (e.g., helicity or spin flip) may change. In the case of many measurements not all states in the system are resolved due to the finite resolution of the electron beams used. In this case 'effective elastic cross sections' are determined which may be referred to as 'rotationally unresolved, vibrationally unresolved, electronically unresolved etc. Elastic scattering is important since, although there are no immediate changes in the target the range and hence spatial extent of the electrons is determined by such scattering.

Elastic cross sections are usually measured at specific energies and angles. These data are used to determine the 'total elastic cross section' by integrating over the entire angular range $(4 \pi)$. The total elastic cross section at given electron impact energy $E_{i}$ is given by:

$$
Q_{e l}\left(E_{i}\right)=\int_{0}^{4 \pi} \frac{d \sigma(k ; \theta, \varphi)}{d \Omega} d \Omega
$$

where $\frac{d \sigma(k ; \theta, \varphi)}{d \Omega}$ is the elastic differential cross section, $(\theta, \varphi)$ are the scattering angles and $k$ is the wave-vector magnitude.

Elastic scattering is one of the best-studied electron collision processes and provides one of the best tests of developing theoretical calculations of electron-molecule scattering. The development of the magnetic angle changing method [42] to extend differential cross section measurements to the full range of scattering angles from $0^{\circ}$ to $180^{\circ}$ has significantly improved the accuracy of total elastic cross sections, particularly for molecules with dipole moments, where elastic scattering is strongly forward peaked.

Elastic scattering cross sections have been reported for all the primary molecules $\mathrm{H}_{2} \mathrm{O}, \mathrm{CO}, \mathrm{CO}_{2}$, $\mathrm{O}_{2}, \mathrm{CH}_{4}, \mathrm{C}_{2} \mathrm{H}_{2}, \mathrm{CH}_{3} \mathrm{OH}, \mathrm{NH}_{3}, \mathrm{HCN}$ and $\mathrm{H}_{2} \mathrm{~S}$. Elastic scattering cross sections for water have been discussed in detail as part of a wider review of electron scattering from water by Itikawa and Mason [3]. An updated review has recommended the corrected data of Khakoo et al. ([43] and erratum) for low energy scattering and Munoz et al. [44] for higher energies (where experiment and theoretical evaluations merge). The benchmarking swarm paper by de Urquijo et al. [45] on cross sections for water reproduced measured transport data in water/helium mixtures and presented the integral cross sections that are entirely self-consistent with the available total cross sections as well as the swarm data over a large range of reduced electric field, E/N.

Cross sections for elastic scattering from methane and acetylene have recently been compiled and evaluated by Song et al. [46,47]. Compilations of data for other molecules are less recent and more fragmented and should be updated. Due to its toxicity, there are few measurements of the elastic scattering cross section from $\mathrm{HCN}$ and therefore there is more reliance on theoretical calculations (e.g., Sanz et al. [48]).

In elastic collisions electrons do not lose energy but change the direction of motion. This is important for models where the kinetics of all particles is taken into account. In more dense plasmas the elastic momentum transfer cross section, defined as integrated DCS with the weight of $(1-\cos \theta)$ over all scattering angles, is a more relevant quantity. Differential cross sections, although being one of the basic properties that defines electron-atom/molecule interactions, are known with relatively low accuracy. In order to illustrate the current status of the agreement of DCS amongst different experiments and theories, the case of absolute cross sections for elastic electron scattering by argon atom is presented in Figure 4. It can be seen that although at first sight all values group around the averaged values, it should be noted that the data are plotted on a logarithmic scale and that there is almost an order of magnitude disagreement for particular data points. 


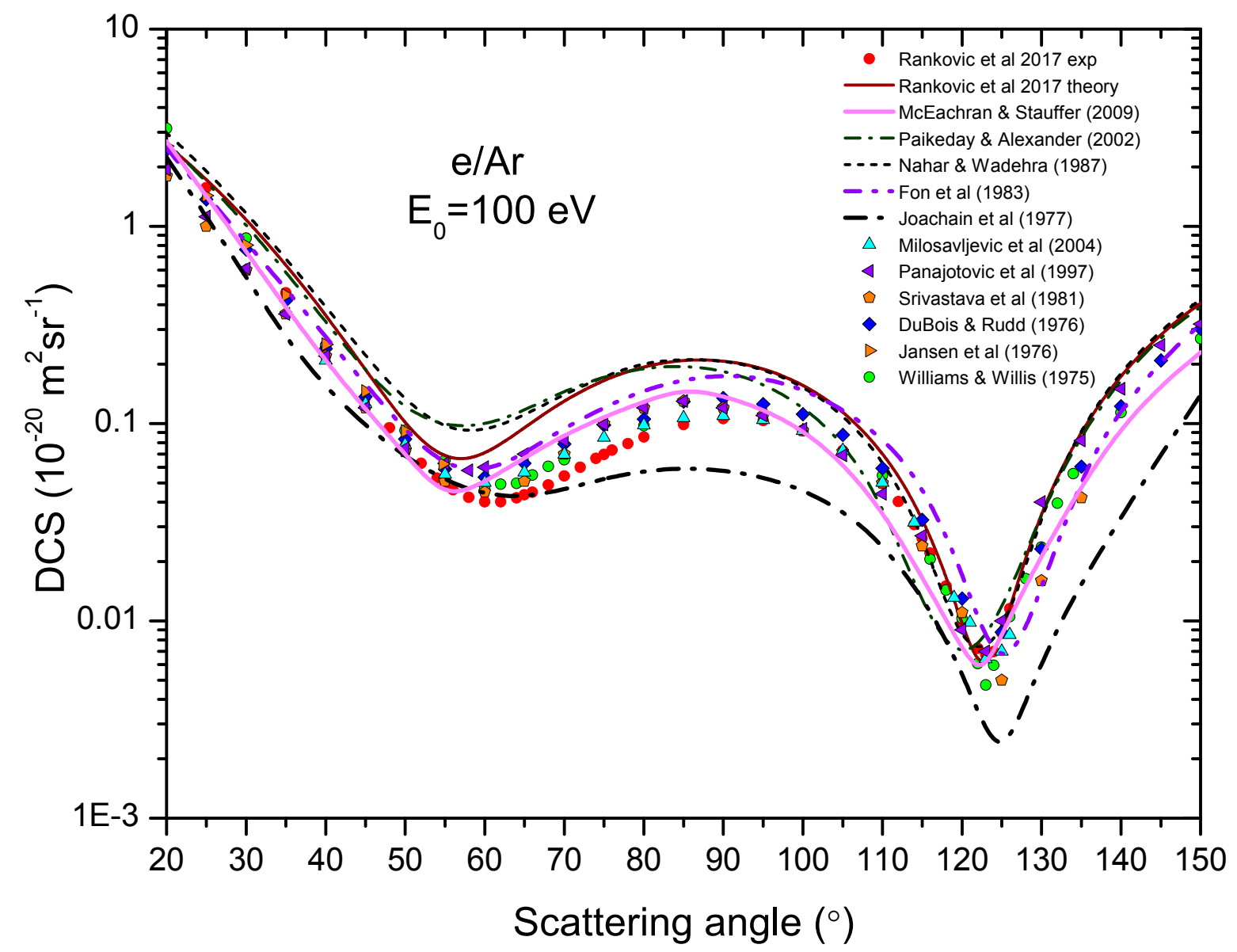

Figure 4. DCS for elastic electron scattering by argon atom at $100 \mathrm{eV}$ impact energy. The data symbols used correspond to: (red circles), Rankovic et al. [49] experiment; (dark red full line), Rankovic et al. [49] theory; (magenta solid line), McEachran and Stauffer [50]; (olive dash dot line), Paikeday and Alexander [51]; (dotted line), Nahar and Wadehra [52]; (violet dash dot dot line), Fon et al. [53]; (cyan dash dot line), McCarthy et al. [54]; (dashed line), Joachain et al. [55]; (cyan up triangles), Milosavljević et al. [56]; (violet left triangle), Panajotović et al. [57]; (orange pentagons), Srivastava et al. [58]; (blue diamond), DuBois and Rudd [59]; (orange right triangles), Jansen et al. [60]; (green circles), Williams and Willis [61].

\subsection{Electron Impact Ionisation Cross Sections}

Most of the ions observed in the comet ion tail are the result of photoionisation of the primary ice species and since there are fewer high energy electrons, electron induced ionisation in comets is likely to be a minor process in total ion yields. However, the mass spectrometric analysis of compounds observed on Rosetta (e.g., using the Rosina instrument) rely upon knowing the fragmentation patterns of candidate molecules which, when compared with the instrument sensitivity, can be used to calculate the relative abundances of the detected molecules. Traditionally mass spectrometers operate with electron energies of $70 \mathrm{eV}$, close to but not at, the maximum of total ionisation cross sections. Branching ratios for fragments of electron impact ionisation are available in many databases (e.g., NIST Chemistry WebBook [62]) however, whilst these ratios are often known the cross sections are not presented. These cross sections may be derived if the total ionisation cross section is known. Total ionisation cross sections may be measured to an accuracy of $<10 \%$ while semi-empirical calculations provide reliable cross sections (at least above $100 \mathrm{eV}$ ). Data on all of the primary molecules $\mathrm{H}_{2} \mathrm{O}, \mathrm{CO}, \mathrm{CO}_{2}$, $\mathrm{CH}_{4}, \mathrm{C}_{2} \mathrm{H}_{2}, \mathrm{CH}_{3} \mathrm{OH}, \mathrm{NH}_{3}, \mathrm{HCN}$ and $\mathrm{H}_{2} \mathrm{~S}$ exist with an accuracy sufficient for providing reliable data for determining their concentrations in the cometary coma and atmosphere. The recent review by 
Tanaka et al. [63] covered this topic in detail employing scaled plane-wave Born models in order to provide comprehensive and absolute integral cross sections, first for ionization and then to optically allowed electronic-state excitation.

\subsection{Anion Production}

Anions have been observed in comets and may be formed by a variety of processes including radiative electron attachment, polar photodissociation, proton transfer and Dissociative Electron Attachment (DEA) where an incident electron is captured by the molecular target $(\mathrm{AB})$ to form an excited state of the molecular negative ion $\mathrm{AB}^{-}$. This state, a Temporary Negative Ion (TNI), generally decays by ejecting the excess electron within a finite time (a process called autodetachment) but the molecular negative ion may also decay through dissociation leading to the formation of a stable negative ion B- and a neutral (often radical) fragment (A). DEA to the list molecules have been studied, identifying the fragment channels but there are few absolute cross sections. Node of VAMDC, the IDEADB maintained by University of Innsbruck, that serves data about dissociative electron attachment to molecules, lists more than 120 different fragments resulting from this process [64]. Anion data from comet 67P is still under evaluation but earlier studies from the Giotto spacecraft of comet 1P/Halley led to a combined chemical/hydrodynamic model for the coma of comet Halley to explore various anion production mechanisms and compute the abundances of atomic and molecular anions as a function of radius in the coma [65]. The dominant anion production mechanisms are found to be polar photodissociation of water and radiative electron attachment to carbon chains in the inner coma, followed by proton transfer from $\mathrm{C}_{2} \mathrm{H}_{2}$ and $\mathrm{HCN}$ to produce $\mathrm{C}_{2} \mathrm{H}^{-}$and $\mathrm{CN}^{-}$, respectively. However, in the outer regions of the coma where electron temperatures reach $10^{3}-10^{5} \mathrm{~K}$, dissociative electron attachment may become a dominant process. Similar effects may be understood for comet 67P. DEA to water yields $\mathrm{H}^{-}$and $\mathrm{OH}^{-}$and $\mathrm{O}^{-}$from $\mathrm{CO}$ and $\mathrm{O}_{2}$ so there are many candidates for production of anions in comet 67P. DEA to all of the primary comet species (and most of the larger more complex species in Table 1) has been reported with DEA fragments recorded from near zero to the ionisation energy pathways. Nevertheless, very few absolute cross sections are available.

\subsection{Electron Impact Excitation and Dissociation}

Electron impact excitation and dissociative excitation of molecular systems is a critical process for a study of cometary coma and its tenuous atmosphere. As discussed above, OSIRIS and ALICE data from Rosetta shows the electron induced dissociation of water may be the source of the $\mathrm{O} I$ line at $135.6 \mathrm{~nm}$ while electron impact by $\mathrm{CO}$ and $\mathrm{CO}_{2}$ yields $\mathrm{C}$ I lines at 156.1 and $165.7 \mathrm{~nm}$. However, this hypothesis is handicapped by the dearth of data on electron impact excitation and electron induced neutral fragmentation for all molecules, not just those of immediate comet interest. This lack of experimental data can be attributed to difficulties in measuring neutral atoms and molecules. When an atom or molecule is in an excited state it may decay (fluoresce) with the emitted light being detected. Such experiments may identify some fragmentation or de-excitation pathways but the sensitivity of the optical detector and ability to 'capture' all of the emitted photons as well as the problem of cascades from higher lying states into the decaying state make measurements of absolute cross sections difficult. Furthermore, some excited states decay to 'dark' non-fluorescent or metastable states which makes them hard to detect. Although metastable fragments may be detected directly by surface ionization they will suffer from the same problems as photon detection i.e., cascade contributions may dominate $[66,67]$. Presently there are few experiments measuring electronically excited fragments by optical or metastable spectroscopy and more experiments are to be encouraged, building on the recent commissioning of electron induced fluorescence (EIF) experiment in Comenius University Bratislava. Figure 5 shows the $\mathrm{H}$ atom spectra recorded by electron impact of molecular hydrogen. This experiment is well equipped to study EIF of water, $\mathrm{CO}$ and $\mathrm{CO}_{2}$ as required for cometary studies although, due to the low cross sections, data collection periods may be days or even weeks placing stringent conditions on the stability of the incident electron and gas beams. 


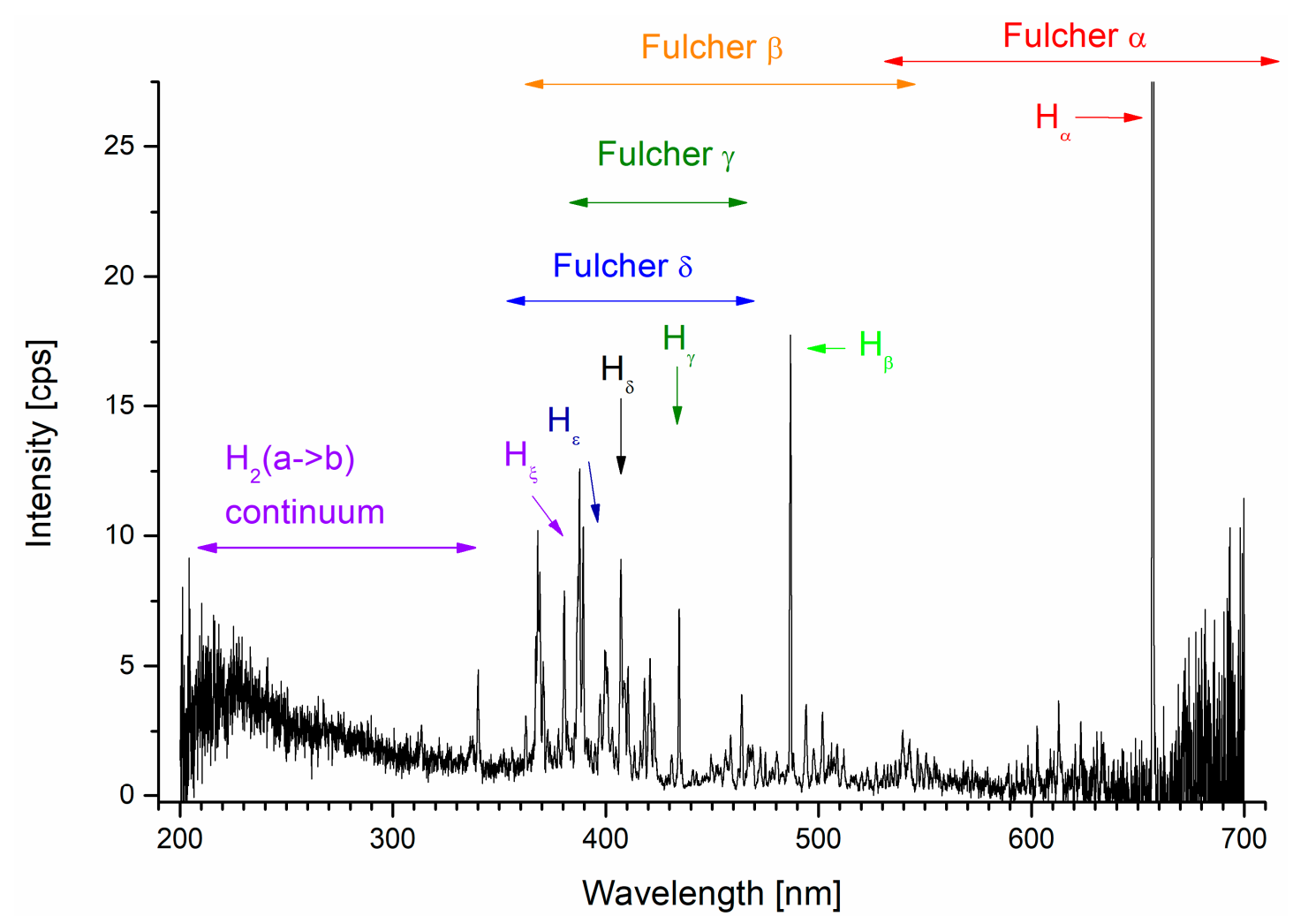

Figure 5. Electron induced fluorescence of the $\mathrm{H}_{2}$ molecule-Balmer lines and Fulcher $\alpha$ system. Measurements performed by Danko et al. [68].

Electron Energy loss spectroscopy monitors the energy of the incident electron post collision and may also be used to probe the direct excitation cross section of the parent molecule excited states but cannot provide data on the fragmentation patterns of that excited state as it decays. Furthermore, in most molecules the electronically excited states are both close together and overlap their ro-vibrational bands, making deconvolution very difficult if discrete electronic excitation cross sections are to be derived.

Finally, the production of neutral fragments in their ground state must be considered. Photon and electron induced dissociation produces many fragments in their ground state where ground state in this case includes fragments that are ro-vibrationally excited but still in the electronic ground state. This low internal energy precludes their detection by fluorescence since IR detection has not proven possible due to IR sources in the apparatus (e.g., electron filaments). Several alternative methods have been proposed to detect ground state neutral fragments including using a second electron beam to ionize the product, or use of surfaces to 'getter' the fragments. In the current context, there are only two experiments relevant to the modelling of electron dissociation of primary comet molecules-that of Harb et al. [69] measuring $\mathrm{OH}$ radical production from water and $\mathrm{C}$ and $\mathrm{O}$ from $\mathrm{CO}$ by Cosby et al. [70] using a fast beam method.

Further experimental studies on electron impact dissociation to neutral fragments will not only benefit the cometary community but the wider electron chemistry community with applications in many plasma systems, aeronomy and radiation chemistry. However, given the experimental difficulty much of the necessary data may be provided by theoretical calculations, which require more detailed exploration.

\section{Possibility of Electron Induced Surface Chemistry}

As discussed above (Section 2.3) many of the larger more complex molecules observed by COSAC and Ptolemy on the Philae lander may be made by addition reactions from simpler molecules. How 
are such reactions induced? Photodissociation has been considered the primary process but electron induced chemistry within ices has been shown to be an efficient route to molecular synthesis and simple electron irradiation of primary ices has been shown to be produce most (all) of the larger molecular species. For example, Figure 6 shows the yield of formamide in an ice film composed of $\mathrm{CO}$ and $\mathrm{NH}_{3}$ as a function of electron energy [71]. The ice was prepared with a mixing ratio of 1:8 and thickness corresponding to 12-18 monolayers and an electron exposure of $200 \mu \mathrm{C} / \mathrm{cm}^{2}$. Formamide is readily formed and the resonance like feature between 6 and $12 \mathrm{eV}$ is characteristic of the synthesis by reactants prepared in a dissociative electron attachment process [71]. Similar experiments have shown that as many as 15 products can be formed by electron irradiation of pure methanol ices [72] including ethylene glycol and methyl formate whilst formamide $\mathrm{HCONH}_{2}$ is formed in irradiation of binary mixtures of ammonia and methanol ice and the simplest amino acid glycine from irradiation of a methylamine and carbon dioxide ice [73]. Thus, electron induced synthesis of simple cometary ices may be a route to formation of several of the organic species observed in surface material from comet 67P.

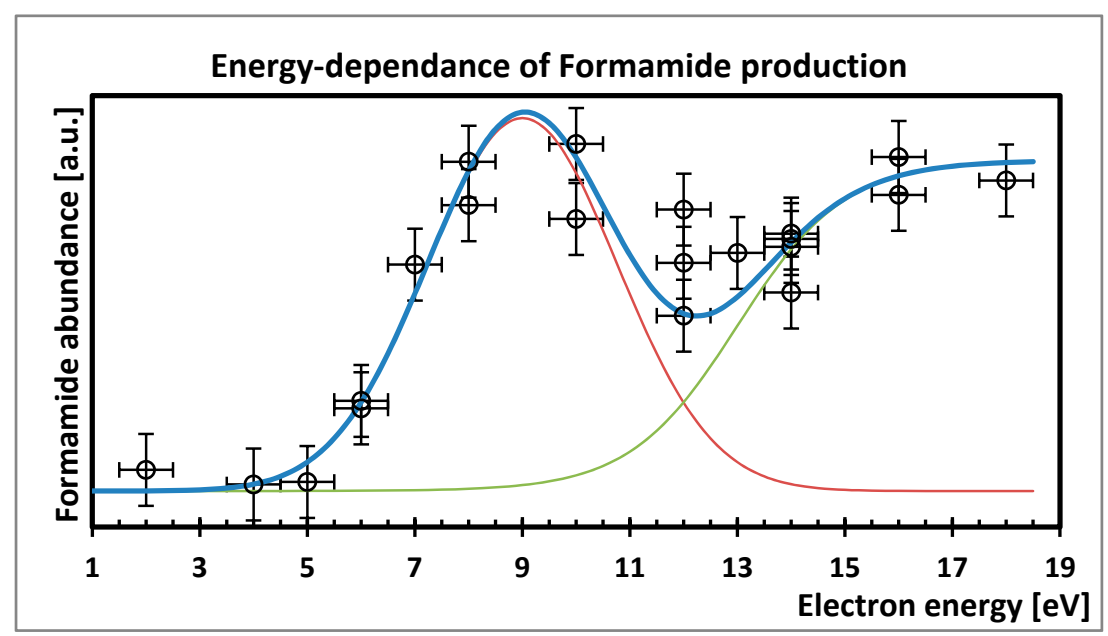

Figure 6. The production of formamide present in mixed multilayer films of $\mathrm{CO}$ and $\mathrm{NH}_{3}$. The resonance like feature (red line) between 6 and $12 \mathrm{eV}$ is characteristic of the synthesis of formamide by reactants prepared in a DEA process, Bredehöft et al. [71].

The route by which molecular oxygen was formed as the fourth most abundant compound in the coma observed by Rosetta, is still subject to debate. However, laboratory experiments $[74,75]$ have shown that radiolysis of water by both electrons and photons yields molecular oxygen but also copious amounts of hydrogen peroxide. Furthermore, comparative experiments between photon and electron irradiation show that electron induced yields are higher for the same energy. Whether this is due to penetration depth of electrons or that electrons open more dissociative pathways (through dipole or spin forbidden transitions) is unknown. The role of electron induced chemistry in comets, in ice covered planetary and lunar objects and in the rich chemistry of the interstellar medium is therefore an emerging topic of modern astronomy and one that has been encouraged by the results of the Rosetta mission.

\section{Conclusions}

In this paper, we have presented a review of recent results from the Rosetta mission to comet 67P/Churyumov-Gerasimenko. The role of electron induced processes has been highlighted with the emission of [O I] lines in the coma explained by the process of electron impact dissociation of water. The role of other electron processes e.g., in the production of the unexpectedly large amounts of molecular oxygen in the coma, is handicapped by lack of detailed knowledge of electron impact 
cross sections We have reviewed the need for electron scattering data and discussed how such data should be collated and reviewed in electron scattering databases. The BEAMD database which is a part of a larger consortium of Virtual Atomic and Molecular Data Centre-VAMDC has been used as an example of modern generation of databases.

The importance of electron processes in comet 67P/Churyumov-Gerasimenko highlights the need for closer interactions and joint projects between the cometary and electron communities and this paper has identified some topics for joint research.

Acknowledgments: BPM recognizes support from MESTD-RS project \#OI 171020 and the grant under 2016 VAMDC Consortium Call-\#1. VV and DJ recognizes support from MESTD-RS project \#III 44002. NJM recognizes support from Europlanet 2020 RI, which has received funding from the European Union's Horizon 2020 research and innovation programme under grant agreement number 654208 and ELEvaTE grant agreement number 692335, as well as the support of the UK STFC and the Leverhulme trust. We thank Juraj Országh for providing us with the unpublished figure of the hydrogen spectrum (Figure 5).

Author Contributions: B.P.M. wrote Section 2.1, Section 2.2, parts of Section 3 and provided Figures 1-4. J.H.B. wrote Section 2.3, provided Figure 6 and Table 1 and provided language editing. V.V. and D.J. wrote Section 3.2. N.J.M. wrote Sections 2, 4 and 5 and edited the paper. B.P.M. is responsible for maintaining electron cross section data in BEAMDB, while V.V. and D.J. are responsible for maintaining the database according to the VAMDC standards.

Conflicts of Interest: The authors declare no conflict of interest.

\section{References}

1. Altwegg, K.; Balsiger, H.; Bar-Nun, A.; Berthelier, J.J.; Bieler, A.; Bochsler, P.; Briois, C.; Calmonte, U.; Combi, M.; De Keyser, J.; et al. 67P/Churyumov-Gerasimenko, a Jupiter family comet with a high D/H ratio. Science 2015, 347. [CrossRef] [PubMed]

2. Feldman, P.D.; A'Hearn, M.F.; Bertaux, J.-L.; Feaga, L.M.; Parker, J.W.; Schindhelm, E.; Steffl, A.J.; Stern, S.A.; Weaver, H.A.; Sierks, H.; et al. Measurements of the near-nucleus coma of comet 67P/Churyumov-Gerasimenko with the Alice far-ultraviolet spectrograph on Rosetta. Astron. Astrophys. 2015, 583, A8. [CrossRef]

3. Itikawa, Y.; Mason, N.J. Cross Sections for Electron Collisions with Water Molecules. Phys. Chem. Ref. Data 2005, 34, 1-22. [CrossRef]

4. Galand, M.; Héritier, K.L.; Odelstad, E.; Henri, P.; Broiles, T.W.; Allen, A.J.; Altwegg, K.; Beth, A.; Burch, J.L.; Carr, C.M.; et al. Ionospheric plasma of comet 67P probed by Rosetta at 3 au from the Sun. Mon. Not. R. Astron. Soc. 2016, S331-S351. [CrossRef]

5. Héritier, K.L.; Henri, P.; Vallières, X.; Galand, M.; Odelstad, E.; Eriksson, A.I.; Johansson, F.L.; Altwegg, K.; Behar, E.; Beth, A.; et al. Vertical structure of the near-surface expanding ionosphere of comet 67P probed by Rosetta. Mon. Not. R. Astron. Soc. 2017, S130-S141. [CrossRef]

6. Bodewits, D.; Lara, L.M.; A'Hearn, M.F.; La Forgia, F.; Gicquel, A.; Kovacs, G.; Knollenberg, J.; Lazzarin, M.; Lin, Z.-Y.; Shi, X.; et al. Changes in the physical environment of the inner coma of 67P/Churyumov-Gerasimenko with decreasing heliocentric distance. Astron. J. 2016, 152. [CrossRef]

7. Krüger, H.; Goesmann, F.; Giri, C.; Wright, I.; Morse, A.; Bredehöft, J.H.; Ulamec, S.; Cozzoni, B.; Ehrenfreund, P.; Gautier, T.; et al. Decay of COSAC and Ptolemy mass spectra at comet 67P/Churyumov-Gerasimenko. Astron. Astrophys. 2017, 600, A56. [CrossRef]

8. Goesmann, F.; Rosenbauer, H.; Bredehöft, J.H.; Cabane, M.; Ehrenfreund, P.; Gautier, T.; Giri, C.; Krüger, H.; Le Roy, L.; MacDermott, A.J.; et al. Organic compounds on comet 67P/Churyumov-Gerasimenko revealed by COSAC mass spectrometry. Science 2015, 349. [CrossRef] [PubMed]

9. Altwegg, K.; Balsiger, H.; Berthelier, J.J.; Bieler, A.; Calmonte, U.; Fuselier, S.A.; Goesmann, F.; Gasc, S.; Gombosi, T.I.; Le Roy, L.; et al. Organics in comet 67P-A first comparative analysis of mass spectra from ROSINA-DFMS, COSAC and Ptolemy. Mon. Not. R. Astron. Soc. 2017, S130-S141. [CrossRef]

10. Wright, I.P.; Sheridan, S.; Barber, S.J.; Morgan, G.H.; Andrews, D.J.; Morse, A.D. CHO-bearing organic compounds at the surface of 67P/Churyumov-Gerasimenko revealed by Ptolemy. Science 2015, 349. [CrossRef] [PubMed] 
11. Bieler, A.; Altwegg, K.; Balsiger, H.; Bar-Nun, A.; Berthelier, J.-J.; Bochsler, P.; Briois, C.; Calmonte, U.; Combi, M.; De Keyser, J.; et al. Abundant molecular oxygen in the coma of comet 67P/Churyumov-Gerasimenko. Nature 2015, 526, 678-681. [CrossRef] [PubMed]

12. Carr, C.; Cupido, E.; Lee, C.G.Y.; Balogh, A.; Beek, T.; Burch, J.L.; Dunford, C.N.; Eriksson, A.I.; Gill, R.; Glassmeier, K.H.; et al. RPC: The Rosetta Plasma Consortium. Space Sci. Rev. 2007, 128, 629-647. [CrossRef]

13. Burch, J.L.; Goldstein, R.; Cravens, T.E.; Gibson, W.C.; Lundin, R.N.; Pollock, C.J.; Winningham, J.D.; Young, D.T. RPC-IES: The Ion and Electron Sensor of the Rosetta Plasma Consortium. Space Sci. Rev. 2007, 128, 697-712. [CrossRef]

14. Eriksson, A.I.; Boström, R.; Gill, R.; Åhlén, L.; Jansson, S.-E.; Wahlund, J.-E.; André, M.; Mälkki, A.; Holtet, J.A.; Lybekk, B.; et al. RPC-LAP: The Rosetta Langmuir Probe Instrument. Space Sci. Rev. 2007, 128, 723-744. [CrossRef]

15. Trotignon, J.G.; Michau, J.L.; Lagoutte, D.; Chabassière, M.; Chalumeau, G.; Colin, F.; Décréau, P.M.E.; Geiswiller, J.; Gille, P.; Grard, R.; et al. RPC-MIP: The Mutual Impedance Probe of the Rosetta Plasma Consortium. Space Sci. Rev. 2007, 128, 713-728. [CrossRef]

16. Cravens, T.E.; Kozyra, J.U.; Nagy, A.F.; Gombosi, T.I.; Kurtz, M. Electron impact ionization in the vicinity of comets. J. Geophys. Res. Space 1987, 92, 7341-7353. [CrossRef]

17. Edberg, N.J.T.; Eriksson, A.I.; Odelstad, E.; Henri, P.; Lebreton, J.P.; Gasc, S.; Rubin, M.; André, M.; Gill, R.; Johansson, E.P.G.; et al. Spatial distribution of low-energy plasma around comet 67P/CG from Rosetta measurements. Geophys. Res. Lett. 2015, 42, 4263-4269. [CrossRef]

18. Clark, G.; Broiles, T.W.; Burch, J.L.; Collinson, G.A.; Cravens, T.; Frahm, R.A.; Goldstein, J.; Goldstein, R.; Mandt, K.; Mokashi, P.; et al. Suprathermal electron environment of comet 67P/Churyumov-Gerasimenko: Observations from the Rosetta Ion and Electron Sensor. Astron. Astrophys. 2015, 583, A24. [CrossRef]

19. Broiles, T.W.; Burch, J.L.; Chae, K.; Clark, G.; Cravens, T.E.; Eriksson, A.; Fuselier, S.A.; Frahm, R.A.; Gasc, S.; Goldstein, R.; et al. Statistical analysis of suprathermal electron drivers at 67P/Churyumov-Gerasimenko. Mon. Not. R. Astron. Soc. 2016, 462, S312-S322. [CrossRef]

20. Deca, J.; Divin, A.; Henri, P.; Eriksson, A.; Markidis, S.; Olshevsky, V.; Horányi, M. Electron and Ion Dynamics of the Solar Wind Interaction with a Weakly Outgassing Comet. Phys. Rev. Lett. 2017, 118. [CrossRef] [PubMed]

21. Le Roy, L.; Wegg, K.; Balsiger, H.; Berthelier, J.-J.; Bieler, A.; Briois, C.; Calmonte, U.; Combi, M.R.; De Keyser, J.; Dhooghe, F.; et al. Rosetta mission results pre-perihelion Special feature Inventory of the volatiles on comet 67P/Churyumov-Gerasimenko from Rosetta/ROSINA. Astron. Astrophys. 2015, 583, A1. [CrossRef]

22. Calmonte, U.; Altwegg, K.; Balsiger, H.; Berthelier, J.J.; Bieler, A.; Cessateur, G.; Dhooghe, F.; van Dishoeck, E.F.; Fiethe, B.; Fuselier, S.A.; et al. Sulphur-bearing species in the coma of comet 67P/Churyumov-Gerasimenko. Mon. Not. Roy. Astron. Soc. 2016, 462, S253-S273. [CrossRef]

23. Pitchford, L.C.; Alves, L.L.; Bartschat, K.; Biagi, S.F.; Bordage, M.-C.; Bray, I.; Brion, C.E.; Brunger, M.J.; Campbell, L.; Chachereau, A.; et al. LXCat: An Open-Access, Web-Based Platformfor Data Needed for Modeling LowTemperature Plasmas. Plasma Process. Polym. 2016, 14. [CrossRef]

24. Wakelam, V.; Herbst, E.; Loison, J.-C.; Smith, I.W.M.; Chandrasekaran, V.; Pavone, B.; Adams, N.G.; Bacchus-Montabonel, M.-C.; Bergeat, A.; Béroff, K.; et al. A KInetic Database for Astrochemistry (KIDA). Astrophys. J. Suppl. Ser. 2012, 199. [CrossRef]

25. Hibbert, A. Calculation of Rates of 4p-4d Transitions in Ar II. Atoms 2017, 5, 8. [CrossRef]

26. Dubernet, M.L.; Antony, B.K.; Ba, Y.A.; Babikov, Y.L.; Bartschat, K.; Boudon, V.; Braams, B.J.; Chung, H.-K.; Daniel, F.; Delahaye, F.; et al. The virtual atomic and molecular data centre (VAMDC) consortium. J. Phys. B 2016. [CrossRef]

27. VAMDC Dictionary. Available online: http:/ / dictionary.vamdc.eu/ (accessed on 30 August 2017).

28. Marinković, B.P.; Jevremović, D.; Srećković, V.A.; Vujčić, V.; Ignjatović, L.M.; Dimitrijević, M.S.; Mason, N.J. BEAMDB and MolD—Databases for atomic and molecular collisional and radiative processes: Belgrade nodes of VAMDC. Eur. Phys. J. D 2017, 71. [CrossRef]

29. Denifl, S.; Garcia, G.; Huber, B.A.; Marinković, B.P.; Mason, N.; Postler, J.; Rabus, H.; Rixon, G.; Solov'yov, A.V.; Suraud, E.; et al. Radiation damage of biomolecules (RADAM) database development: Current status. J. Phys. Conf. Ser. 2013, 438. [CrossRef] 
30. Register, D.F.; Trajmar, S.; Srivastava, S.K. Absolute elastic differential electron scattering cross sections for He: A proposed calibration standard from 5 to 200 eV. Phys. Rev. A 1980, 21, 1134-1151. [CrossRef]

31. Maljković, J.B.; Blanco, F.; García, G.; Marinković, B.P.; Milosavljević, A.R. Elastic electron scattering from formamide molecule. Nucl. Instrum. Methods Phys. Res. B 2012, 279, 124-127. [CrossRef]

32. Belić, D.S.; Urbain, X.; Cherkani-Hassani, H.; Defrance, P. Electron-impact dissociation and ionization of CN+ ions. Phys. Rev. A 2017, 95. [CrossRef]

33. Huebner, W.F. Composition of comets: Observations and models. Earth Moon Planets 2002, 89, $179-195$. [CrossRef]

34. Campbell, L.; Brunger, M.J. Modelling of plasma processes in cometary and planetary atmospheres. Plasma Sources Sci. Technol. 2013, 22. [CrossRef]

35. Simmons, J.D.; Bass, A.M.; Tilford, S.G. The Fourth Positive System of Carbon Monoxide Observed in Absorption at High Resolution in the Vacuum Ultraviolet Region. Astrophys. J. 1969, 155, 345-358. [CrossRef]

36. Campbell, L.; Brunger, M.J. Electron collisions in atmospheres. Int. Rev. Phys. Chem. 2016, 35, $297-351$. [CrossRef]

37. Zecca, A.; Karwasz, G.P.; Brusa, R.S. One century of experiments on electron-atom and molecule scattering. A critical review of integral cross-sections, I. Atoms and diatomic molecules. Riv. Nuovo Cimento 1996, 19, 1-146. [CrossRef]

38. Bransden, B.H.; McDowell, M.R.C. Electron scattering by atoms at intermediate energies II. Theoretical and experimental data for light atoms. Phys. Rep. 1978, 46, 249-394. [CrossRef]

39. Brunger, M.J.; Buckman, S.J. Electron-molecule scattering cross-sections. I. Experimental techniques and data for diatomic molecules. Phys. Rep. 2002, 357, 215-458. [CrossRef]

40. Flower, D.R. Molecular collision processes in interstellar clouds. Phys. Rep. 1989, 174, 1-66. [CrossRef]

41. Anzai, K.; Kato, H.; Hoshino, M.; Tanaka, H.; Itikawa, Y.; Campbell, L.; Brunger, M.J.; Buckman, S.J.; Cho, H.; Blanco, F; et al. Cross section data sets for electron collisions with $\mathrm{H}_{2}, \mathrm{O}_{2}, \mathrm{CO}, \mathrm{CO}_{2}, \mathrm{~N}_{2} \mathrm{O}$ and $\mathrm{H}_{2} \mathrm{O}$. Eur. Phys. J. D 2012, 66. [CrossRef]

42. King, G.C. The Use of the Magnetic Angle Changer in Electron Spectroscopy. In Changer in Electron Scattering. Physics of Atoms and Molecules; Whelan, C.T., Mason, N.J., Eds.; Springer: Boston, MA, USA, 2005; pp. 111-120.

43. Khakoo, M.A.; Silva, H.; Muse, J.; Lopes, M.C.A.; Winstead, C.; McKoy, V. Electron scattering from $\mathrm{H}_{2} \mathrm{O}$ : Elastic scattering. Phys. Rev. A 2008, 78. [CrossRef]

44. Muñoz, A.; Oller, J.C.; Blanco, F.; Gorfinkiel, J.D.; Limão-Vieira, P.; Maira-Vidal, A.; Borge, M.J.G.; Tengblad, O.; Huerga, C.; Téllez, M.; et al. Energy deposition model based on electron scattering cross section data from water molecules. J. Phys. Conf. Ser. 2008, 133. [CrossRef]

45. de Urquijo, J.; Basurto, E.; Juárez, A.M.; Ness, K.F.; Robson, R.E.; Brunger, M.J.; White, R.D. Electron drift velocities in He and water mixtures: Measurements and an assessment of the water vapour cross-section sets. J. Chem. Phys. 2014, 141. [CrossRef] [PubMed]

46. Song, M.-Y.; Yoon, J.-S.; Cho, H.; Itikawa, Y.; Karwasz, G.P.; Kokoouline, V.; Nakamura, Y.; Tennyson, J. Cross Sections for Electron Collisions with Methane. J. Phys. Chem. Ref. Data 2015, 44. [CrossRef]

47. Song, M.-Y.; Yoon, J.-S.; Cho, H.; Karwasz, G.P.; Kokoouline, V.; Nakamura, Y.; Tennyson, J. Cross Sections for Electron Collisions with Acetylene. J. Phys. Chem. Ref. Data 2017, 46. [CrossRef]

48. Sanz, A.G.; Fuss, M.C.; Blanco, F.; Sebastianelli, F.; Gianturco, F.A.; García, G. Electron scattering cross sections from $\mathrm{HCN}$ over a broad energy range (0.1-10 $000 \mathrm{eV})$ : Influence of the permanent dipole moment on the scattering process. J. Chem. Phys. 2012, 137. [CrossRef] [PubMed]

49. Ranković, M.L.; Maljković, J.B.; Tökesi, K.; Marinković, B.P. Elastic electron differential cross sections for argon atom in the intermediate energy range from $40 \mathrm{eV}$ to $300 \mathrm{eV}$. Eur. Phys. J. D 2017, submitted.

50. McEachran, R.P.; Stauffer, A.D. An optical potential method for elastic electron and positron scattering from argon. J. Phys. B 2009, 42. [CrossRef]

51. Paikeday, J.M.; Alexander, J. Polarization Potential for e-Argon Scattering by Differential Scattering Minimization at Intermediate Energies. Int. J. Quant. Chem. 2002, 90, 778-785. [CrossRef]

52. Nahar, S.N.; Wadehra, J.M. Elastic scattering of positrons and electrons by argon. Phys. Rev. A 1987, 35, 2051-2064. [CrossRef]

53. Fon, W.C.; Berrington, K.A.; Burke, P.G.; Hibbert, A. The elastic scattering of electrons from inert gases. III. Argon. J. Phys. B 1983, 16, 307-321. [CrossRef] 
54. McCarthy, I.E.; Noble, C.J.; Phillips, B.A.; Turnbull, A.D. Optical model for electron scattering by inert gases. Phys. Rev. A 1977, 15, 2173-2185. [CrossRef]

55. Joachain, C.J.; Vanderpoorten, R.; Winters, K.H.; Byron, F.W., Jr. Optical model theory of elastic electron- and positron-argon scattering at inter mediate energies. J. Phys. B 1977, 10, 227-238. [CrossRef]

56. Milosavljević, A.R.; Telega, S.; Šević, D.; Sienkiewicz, J.E.; Marinković, B.P. Elastic electron scattering by argon in the vicinity of the high-energy critical minimum. Rad. Phys. Chem. 2004, 70, 669-676. [CrossRef]

57. Panajotović, R.; Filipović, D.M.; Marinković, B.P.; Pejčev, V.; Kurepa, M.; Vušković, L. Critical minima in elastic electron scattering by argon. J. Phys. B 1997, 30, 5875-5894. [CrossRef]

58. Srivastava, S.K.; Tanaka, H.; Chutjian, A.; Trajmar, S. Elastic scattering of intermediate-energy electrons by Ar and Kr. Phys. Rev. A 1981, 23, 2156-2166. [CrossRef]

59. DuBois, R.D.; Rudd, M.E. Differential cross sections for elastic scattering of electrons from argon, neon, nitrogen and carbon monoxide. J. Phys. B 1976, 9, 2657-2667. [CrossRef]

60. Jansen, R.H.J.; de Heer, F.J.; Luyken, H.J.; van Wingerden, B.; Blaauw, H.J. Absolute differential cross sections for elastic scattering of electrons by helium, neon, argon and molecular nitrogen. J. Phys. B 1976, 9, 185-212. [CrossRef]

61. Williams, J.F.; Willis, B.A. The scattering of electrons from inert gases, I. Absolute differential elastic cross sections for argon atoms. J. Phys. B 1975, 8, 1670-1682. [CrossRef]

62. NIST Chemistry WebBook. Available online: http://webbook.nist.gov/chemistry/ (accessed on 30 August 2017).

63. Tanaka, H.; Brunger, M.J.; Campbell, L.; Kato, H.; Hoshino, M.; Rau, A.R.P. Scaled plane-wave Born cross sections for atoms and molecules. Rev. Mod. Phys. 2016, 88, 025004. [CrossRef]

64. IDEADB. Available online: http://ideadb.uibk.ac.at/ (accessed on 18 October 2017).

65. Cordiner, M.A.; Charnley, S.B. Negative ion chemistry in the coma of comet 1P/Halley. Meteorit. Planet. Sci. 2014, 49, 21-27. [CrossRef]

66. Barnett, S.M.; Mason, N.J.; Newell, W.R. Production of the $\mathrm{N}_{2}\left(\mathrm{~A}^{1} \Sigma_{\mathrm{u}+}\right)$ Metastable State by Electron Dissociation of $\mathrm{N}_{2}$ O. Chem. Phys. 1991, 153, 283-295. [CrossRef]

67. Barnett, S.M.; Mason, N.J.; Newell, W.R. Dissociative Excitation of Metastable Fragments by Electron Impact on Carbonyl Sulphide, Carbon Dioxide and Carbon Monoxide. J. Phys B 1992, 25, 1307-1320. [CrossRef]

68. Danko, M.; Ribar, A.; Ďurian, M.; Országh, J.; Matejčík, Š. Electron induced fluorescence of the $\mathrm{H}_{2}$ molecule-Balmer lines and Fulcher $\alpha$ system. Plasma Sources Sci. Technol. 2016, 25. [CrossRef]

69. Harb, T.; Kedzierski, W.; McConkey, J.W. Production of ground state $\mathrm{OH}$ following electron impact on $\mathrm{H}_{2} \mathrm{O}$. J. Chem. Phys. 2001, 115, 5507-5512. [CrossRef]

70. Cosby, P.C. Electron-impact dissociation of carbon monoxide. J. Chem. Phys. 1993, 98, 7804-7818. [CrossRef]

71. Bredehöft, J.H.; Böhler, E.; Schmidt, F.; Borrmann, T.; Swiderek, P. Electron-Induced Synthesis of Formamide in Condensed Mixtures of Carbon Monoxide and Ammonia. ACS Earth Space Chem. 2017, 1, 50-59. [CrossRef]

72. Boyer, M.C.; Rivas, N.; Tran, A.A.; Verish, C.A.; Arumainayagam, C.R. The role of low-energy $(\leq 20 \mathrm{eV})$ electrons in astrochemistry. Surf. Sci. 2016, 652, 26-32. [CrossRef]

73. Mason, N.J.; Nair, B.; Jheeta, S.; Szymańska, E. Electron induced chemistry: A new frontier in astrochemistry. Faraday Discuss. 2014, 168, 235-247. [CrossRef] [PubMed]

74. Zheng, W.; Jewitt, D.; Kaiser, R.I. Formation of Hydrogen, Oxygen and Hydrogen Peroxide in Electron-irradiated Crystalline Water Ice. Astrophys. J. 2006, 639, 534-548. [CrossRef]

75. Zheng, W.; Jewitt, D.; Kaiser, R.I. Temperature Dependence of the Formation of Hydrogen, Oxygen and Hydrogen Peroxide in Electron-Irradiated Crystalline Water Ice. Ice. Astrophys. J. 2006, 648, 753-761. [CrossRef]

(C) 2017 by the authors. Licensee MDPI, Basel, Switzerland. This article is an open access article distributed under the terms and conditions of the Creative Commons Attribution (CC BY) license (http://creativecommons.org/licenses/by/4.0/). 